\title{
Exploring Individual and Interpersonal Level Factors Associated with Academic Success of College Students at a Women's, Faith-based Higher Institution
}

\author{
Angela U. Ekwonye ${ }^{1} \&$ Verna DeLauer $^{2}$ \\ ${ }^{1}$ Department of Public Health, St. Catherine University, St. Paul, Minnesota, USA \\ ${ }^{2}$ Department of Environment Studies, Franklin Pierce University, Rindge, New Hampshire, USA \\ Correspondence: Angela U. Ekwonye, Department of Public Health, St. Catherine University, St. Paul, \\ Minnesota, USA. Tel: 651-690-6928. E-mail: amekwonye034@ stkate.edu
}

Received: December 4, 2018

Accepted: December 21, 2018 Online Published: January 8, 2019

doi:10.5539/hes.v9n1p86

URL: https://doi.org/10.5539/hes.v9n1p86

\begin{abstract}
The present study investigated how spirituality, peer connections, and social integration relate to academic resiliency, academic self-efficacy, academic integration, and institutional commitment of college students who identify as female. A sample of 372 undergraduates (ages 18-26) at a Catholic University completed Mapworks survey containing institution-specific questions and spirituality items in Spring 2018. Pearson correlation was used to examine the bivariate relationships between the variables. Canonical correlation analysis (CCA) was conducted to determine if relationships exist among the predictor variables (spirituality, peer connections, social integration) and the criterion variables (academic resiliency, academic self-efficacy, academic integration, institutional commitment). Academic resiliency was the only contributor to the synthetic criterion variable. The contributions of academic self-efficacy, academic integration and institutional commitment to the synthetic criterion variable were very negligible. Social integration and peer connections were the primary contributors to the predictor synthetic variable, with a secondary contribution by spirituality. Social integration, peer connections, and spirituality were all positively related to academic resiliency. Simultaneously addressing the social and spiritual well-being of college students, particularly those who have self-selected to attend a women's college, are crucial to promoting their academic success.
\end{abstract}

Keywords: academic success, spirituality, social integration, peer connections, faith-based higher institution

\section{Introduction}

\subsection{Background}

Colleges and other educational institutions are settings in which academic challenge, setback, and pressure are a constant reality of everyday life (Cavazos, Johnson, \& Sparrow, 2010; Goldrick-Rab, 2010). Students doing poorly academically may be at risk of failing out of school and thus may have limited access to future opportunities' that may be available to other students who completed their education (Raju \& Schumacker, 2015). The search for attributes associated with college students' academic success has spurred a great deal of empirical research in recent years (George, Dixon, Stansal, Gelb, \& Pheri, 2008; Fife, Bond, \& Byars-Winston, 2011; Shin \& Steger, 2016). Researchers in educational settings have identified academic resiliency, academic self-efficacy, academic integration, and institutional commitment as attributes of academic success (Fife, et al., 2011; Khan, Ali, \& Kausar, 2014; Woosley \& Jones, 2011; Tinto, 1998). Academic resiliency refers to the extent one is willing to put in extra effort to do well in his or her courses amidst setbacks. Academic self-efficacy is the belief in one's ability to persevere and do well even when the courses are challenging. Academic integration is the degree one is keeping current and motivated to complete academic work, while institutional commitment is the degree one intends to persist and complete school (Woosley \& Jones, 2011). Little attention has been paid to some of the critical factors that may be associated with these attributes especially among college students who identify as female ${ }^{1}$ and attend faith-based higher institutions in the United States. Although there are other studies on these attributes of academic success in general, the present work stands out because it is the first study to be conducted in a faith-based higher institution in the United States in which all students identify as women. It is also the first to explore how individual-level factor such as spirituality and interpersonal level factors such as 
peer connections and social integration relate to the academic success of female college students in a multivariate analysis. Spirituality, peer connections, and social integration were chosen as predictors in this study because previous research indicates that females including female college students tend to have greater sense of connection with God or a Higher power and with members of their community and rely on such connections to deal with various life challenges (Buchko, 2004; Bryant, 2007). It has been suggested that female college students experience to a greater extent a strong relational spirituality in terms of daily connection with a higher power through prayer, seek spiritual direction when handling personal problems, feel assured that a higher power is present and active in their lives, derive comfort and security from faith, and express feelings of devotion to and reverence for a higher power compared to their male counterparts (Buchko 2004). More recent scholars are highlighting that intrapersonal growth and cognitive growth are interconnected and should be considered as such at institutions of higher education (Arora, 2017). In addition, feminist scholars are increasingly interested in women's spirituality and its impact on women's rights, calling into question that idea that all notions of spirituality are oppressive to women (Longman, 2018; Aune 2011; Nyhagen \& Halsaa, 2016).

It is not clear whether this greater sense of connection helps college women attending an all-female faith-based higher institution deal with academic rigor. Hence, there is a need to better understand how spirituality, peer connections, and social integration, which are all centered on relationships influence the academic success of this population of women attending a faith-based higher institution. The nature of this institution makes it a good setting for the present study.

${ }^{1}$ Here we encompass all individual interpretations of what it means to be female or consider oneself a woman.

\subsection{Nature of Faith-based Institutions of Higher Education}

Faith-based schools have a particular religious character, are privately-operated, and include schools affiliated to Catholic dioceses and religious orders, Protestant, Jewish, and other religious organizations. Faith-based higher institutions tend to integrate faith and learning into the lives of its students, faculty, and staff, (Trainor, 2006; Grace, 2003). Catholic universities particularly strive to draw on a rich intellectual tradition dating back eight centuries to the founding of the Catholic Universities (Trainor, 2006). The small class sizes, a focus on teaching, attention to ethical reasoning, integration of faith and learning, and a high sense of community are distinctive traits of Catholic colleges and universities (Trainor, 2006; Grace, 2003). Thus, the culture of social capital, strong internal sense of community, structured and disciplined environment, sense of mission, and the vocational commitment of teachers which prevails in faith-based schools are likely to contribute to academic success of their students. Given that spirituality, peer connections, and social integration are the hallmarks of faith-based higher institutions; no research has been done to determine how these factors relate to academic resiliency, self-efficacy, integration and institutional commitment of students in all-female Catholic colleges and universities. Hence, the gap in existing studies provides the basis for the present study.

\subsection{Theoretical Framework}

Developmental psychologists have pointed out a feminine ethics of care, one that transcends subjective notions of gender and is critical for effective democratic communities (Gilligan, 1993; Gilligan, 2014; Larrabee, 2016). Individuals have varying degrees of dependence and interdependence on one another (Gilligan, 2014) and human development and behavior are the results of interactions between individual characteristics and the environment over the course of one's life (Bronfenbrenner, 1994). The ecological environment ranges from the microsystem which includes direct social interactions between the individual and his or her immediate environment such as school and family to macrosystem consisting of societal influence such as cultural values, laws, economy, etc. Direct interaction with, care for, and support from, friends, peers, family members, and teachers appear to have the most influential and greatest impact on an individual including young adults (Bronfenbrenner, 1994). However, an attribute such as spirituality may likewise play an important role in the academic success of college students. Spirituality refers to the sense of well-being that arises from one's relationship with a higher power, people, nature, etc., and the meaning found in these relationships (Weathers, McCarthy, and Coffey 2016). This sense of well-being may be associated with greater academic success. The present study took an ecological perspective and included an aspect of individual characteristics (spirituality), and interpersonal level factors (peer connections and social integration) to better understand their relationships with academic resiliency, academic self-efficacy, academic integration, and institutional commitment among female college students attending a faith-based higher institution.

\subsection{Attributes of Academic Success}

Academic resiliency, academic self-efficacy, academic integration, and institutional commitment are attributes that have been associated with academic success in various college samples (Walker \& Dixon, 2002; George, 
Dixon, Stansal, Gelb, \& Pheri, 2008; Cavazos, Johnson, \& Sparrow, 2010; Fife, Bond, \& Byars-Winston, 2011; Beauvais, Stewart, DeNisco, \& Beauvais, 2014), but it is not clear whether these attributes also apply to female students attending a faith-based higher institution. Abiola and Udofia (2011) defined resilience in terms of inner strength, competence, optimism, flexibility, and the ability to cope effectively when faced with life's challenges. In the academic context, resilience is defined as the increased likelihood of success in school and other life accomplishments in the presence of adversities (Wang, Haertal, \& Walberg, 1994). Academically resilient students are those who succeed despite conditions that place them at risk of poor performance (Waxman et al., 2003) and dropping out of school (Wayman, 2002). Like resilience, self-efficacy is particularly important when individuals face adversity (Bandura et al., 2001). Self-efficacy is the belief in one's ability to organize and execute the course of action required to manage specific situations (Bandura, 1995). Academic self-efficacy plays a key role in college success and is defined as the confidence in one's ability to perform academic-related tasks (Robbins et al., 2004). Positive self-efficacy beliefs are associated with increased motivation and perseverance (Bandura et al., 2001). Likewise, academic integration is a student's potential to benefit from academic experiences, which are based on that student's academic performance and intellectual development within an educational setting (Pascarella \& Terenzini, 1983). Academic integration requires that the student can meet the institution's educational demands by persisting in his or her study (Tinto, 1998) which ultimately results in better educational outcomes, such as better grades and successful graduation (Rienties, Beausaert, Grohnert, Niemantsverdriet, \& Kommers, 2012). Finally, institutional commitment is the degree to which a student persists or drops out of school (Tinto, 1993). Institutional commitment affects attrition decisions as students who feel they do not fit in, may think of leaving the institution, whereas those who feel they belong are more likely to want to stay in school and graduate (Tinto, 1998). Woosley and Miller (2009) found that students who scored high in institutional commitment were more likely to have higher GPA and more committed to staying in school and completing their degree. These studies show that academic resilience, academic self-efficacy, academic integration, and commitment to the institution result in college students' greater academic success, but what is less known are the factors that may be contributing to these outcomes.

\subsection{Spirituality, Peer Connections, Social Integration and Attributes of Academic Success}

Some studies have found a link between spirituality, peer connections, social integration, and attributes of academic success (George, Dixon, Stansal, Gelb, \& Pheri, 2008; Walker \& Dixon, 2002), but there is a complete lack of literature on female students attending a faith-based higher institution.

Spirituality is the process of striving for greater connectedness to self, others, and/or a higher power or nature; from which one derives a sense of meaning in life; and transcendence beyond self, everyday living, and suffering (Weathers, McCarthy, and Coffey 2016). Spirituality provides one with personal meaning, social and inner resources they can call on in adverse situations (Pargament 2001). Individuals who are highly spiritual are able to draw strength from within and thus feel in control of both themselves and situations in which they find themselves (Ekwonye, Cahill, De Luca, \& Cabell, 2017). Although spirituality and religion has been used interchangeably in some studies (Hooker, Masters, \& Carey, 2014), the two constructs are distinct. Spirituality is about having authentic relationships to self, others, the universe, and the transcendent from which one derives vital energy that gives meaning to one's lives (Jones, 2005). Religion on the other hand, is the actual expression of the spiritual connection in form of specific beliefs and practices shared by individuals with similar experiences of transcendence (Hodge, 2001a). It should be noted that spirituality is about connectedness with self, others, nature, higher power, or one's image of the ultimate, thus every individual regardless of living in a secular or religious culture is spiritual. With regard to spirituality in higher education, Tisdell (2001) asserts that spirituality is one of the ways adult students construct knowledge and meaning. Jones (2005) refers to it as transcendence and compassion in the classroom that recognizes the interconnectedness of the students, the teacher, and the subject. Such honest, authentic, and vital connection has been shown to be beneficial to the learning process. For instance, a study of African American college students found that spirituality significantly predicted academic self-efficacy (Fife, Bond, \& Byars-Winston, 2011). Similar findings were reported among 343 Iranian college students (Asghari, Saadat, Atefi Karajvandani, Janalizadeh Kokaneh, 2014). Mehrinejad, Tarsafi, and Rajabimoghadam (2015) reported a significant positive correlation between resiliency and spirituality components using 200 undergraduates and graduates from three universities in Tehran. Morris (2002) found that spirituality was significantly related to a student's decision to remain or leave an institution of Christian higher education. In contrast, Morgan Consoli, Delucio, Noriega, and Llamas (2015) found that spirituality was a significant predictor for thriving but not for the resilience of Latino college students. This inconsistency warrants further investigation.

Regarding the relationship between peer connections and academic resiliency, self-efficacy, integration, and 
institutional commitment, research shows that interpersonal relationships are important and critical in young people's engagement and motivation at school (Martin \& Dowson, 2009). Students can provide emotional support to one another when they talk and listen to each other, or share learning experiences (Furrer, Skinner, \& Pitzer, 2014). Warm interactions with classroom peers create a climate of comfort and help meet students' need for relatedness (Furrer \& Skinner, 2003; Martin \& Dowson, 2009). Over time, warmth and support from peers not only operate as social resources, but help students to construct their motivational resources promoting positive self-perceptions of relatedness, competence, and successful graduation (Martin \& Marsh, 2009; Skinner \& Pitzer, 2012).

Social integration according to Pascarella and Terenzini (1980) is a student's social involvement and interactions with other students including developing friendships, joining clubs and organizations, and informal interactions with faculty and staff. College students who are academically and socially connected with faculty, staff, and their peers are more likely to perform well academically (Pan, Guo, Alikonis, \& Bai, 2008). Students who feel at home in school and well connected to fellow students and teachers are more likely to take part in extra-curricular activities and persist in school (Severiens \& Wolff, 2008). A study of 3,051 first-year college students found that social integration was a significant predictor of institutional commitment (Woosley \& Miller, 2009), and more so in Christian higher institutions (Walter, 2000; Morris, 2002). However, social integration alone may not be sufficient in encouraging academic success if the student does not integrate into the academic community (Tinto, 1998).

The above studies indicate some relationships between spirituality, peer connections, social integration, and the various academic success attributes, yet little is known about the relative contribution of each factor to the academic success of female college students. No study to date has explored how combinations of spirituality, peer connections, and social integration relate to academic resiliency, academic self-efficacy, academic integration, and institutional commitment of students in an all-female faith-based higher institution. So less is known about how this population of college students copes with academic stress. There is also a complete lack of empirical evidence on the relationship between spirituality and academic integration. Therefore, studies are needed to understand the relationships between and among these variables particularly among students in the all-female faith-based higher institution.

\subsection{Present Study and Hypotheses}

Academic resiliency, academic self-efficacy, academic integration, and institutional commitment may be influenced by factors operating at different ecological levels. Spirituality, an individual level attribute (Reed 1987) has been associated with better academic outcome (Cavazos, Johnson, \& Sparrow, 2010; Fife, Bond, \& Byars-Winston, 2011; Beauvais, Stewart, DeNisco, \& Beauvais, 2014). At the interpersonal level, peer connections and social integration have been related to academic resilience, persistence, academic self-efficacy and academic integration in various bivariate analyses (Woosley \& Miller, 2009; Dennis, Phinney, \& Chuateco, 2005; Denning, Brannan, Murphy, Losco, \& Payne, 2018). An investigation of multiple outcome variables academic resiliency, academic self-efficacy, academic integration, and institutional commitment could further elucidate the importance of spirituality, peer connections, and social integration in the college students' experience. Therefore, the present study tested the following hypotheses:

1. Spirituality will be significantly correlated with academic resiliency, academic self-efficacy, academic integration, and institutional commitment.

2. Peer connections will be significantly correlated with academic resiliency, academic self-efficacy, academic integration, and institutional commitment.

3. Social integration will be significantly correlated with academic resiliency, academic self-efficacy, academic integration, and institutional commitment.

4. Combinations of spirituality, peer connections, and social integration will be significantly correlated with academic resiliency, academic self-efficacy, academic integration, and institutional commitment.

\section{Method}

\subsection{Sample and Setting}

The study was conducted at St. Catherine University which is a traditional all-female faith-based (Catholic) higher institution and one of the largest of its kind in the United States. The University has three colleges: Graduate College, College for Women, and College for Adults. The Graduate College and the College for Adults are coeducational, while the College for Women is traditional undergraduate college-age female students. Students in the College for Women were invited to complete the Making Achievement Possible (Mapworks) 
online survey administered in Spring 2018. A total population of 931 students was invited to participate in the study. The 2018 Mapworks online survey contained some spirituality items and institution-specific questions, which were designed to gather information about students' college experience so that necessary support services can be provided primarily to at-risk students.

\subsection{Inclusion/Exclusion}

To be eligible to participate in the study, the student must be currently enrolled at St Catherine University in the College for Women in Spring 2018. Students were excluded if they were not taking classes in that semester.

\subsection{Criterion Variables}

The criterion variables in this study include: academic resiliency, academic self-efficacy, academic integration, and institutional commitment. Academic resiliency was assessed using four Mapworks questions (e.g., "To what extent do you work harder in a course when you get a poor grade?"). Academic self-efficacy was measured with three Mapworks questions (e.g., "To what degree are you certain that you can do well on all problems and tasks assigned in your courses?"). Academic integration was measured using a set of four questions (e.g., "Overall, to what degree are you satisfied with your academic life on campus?"). Institutional commitment was assessed using three Mapworks questions (e.g., "To what degree do you intend to come back to this institution for the next year?"). Participants responded using 7-point Likert-type scales ranging from 1 = "Not at all" to 7 = "Extremely." The scales had good internal consistency ranging from .799 - .883 (Woosley \& Jones, 2011).

\subsection{Predictor Variables}

\subsubsection{Interpersonal Level Factors}

Social integration and peer connections are the two interpersonal level factors assessed in this study. Social Integration was measured using three Mapworks questions (e.g., "Overall to what degree are you fitting in?"), while peer connections was assessed using a set of three Mapworks questions (e.g., "On this campus, to what degree are you connecting with people who share common interests with you?"). Participants responded using 7-point Likert-type scales ranging from $1=$ "Not at all" to $7=$ "Extremely." Responses were summed and averaged, and the scales had good internal consistency ranging from $\alpha .90-.92$. (Woosley \& Jones, 2011).

\subsubsection{Individual Level Factor}

Spirituality is the one individual-level factor measured in this study. Students' spirituality was assessed using a newly developed instrument the "Spiritual Impact Rating Scale for Women (SIRSW)" (Ekwonye, 2018). The creation of the SIRSW and content validation was carried out in phases. The purpose of the first phase was to generate a pool of items for the questionnaire. Items were created after an extensive review of the literature and a cursory inspection of existing spirituality instruments including the comprehensive list of measures of religiosity (Hill \& Hood, 1999). This initial review led to the creation of a total of 22 items relevant to women's spirituality. The 22 items were reviewed for content validity by St. Catherine's University Chaplain, a Catholic nun, three St. Catherine's University graduate and two undergraduate students, and a panel from the University's Office of Institutional Research, Student Support and Retention, and Academic Advising. In the end, 19 items were deemed valid for measuring the influence of spirituality in women population. The instrument was validated using a sample of 554 college women. An exploratory principal component analysis was performed to examine the dimensionality of the SIRSW. Only one component was extracted. Sixteen of the 19 items had loadings ranging from 0.84 to 0.94 . An eigenvalue of 13.1 was obtained accounting for $82.0 \%$ of the variance. The internal consistency reliability estimates with Cronbach's alpha was 0.97 for the 16 -item scale. Some examples of items include 1) "To what extent does your spirituality define your relationships?" 2) "To what extent do your spiritual beliefs help you find meaning in times of hardship." Items are rated and scored on a 7-point scale. Responses range from 1 (Not at all), 4 (Moderately) to 7 (Extremely). The scores were summed up to provide total scores ranging from 16 to 112 , with higher scores indicating higher spirituality.

\subsection{Procedure}

After the Institutional Review Board (IRB) approval, students in the College for Women were invited to complete the University Mapworks online survey through the Office for Student Support and Outreach. Participants completed the consent form which contained information about the purpose of the study, risks and benefits, and the rights to withdraw from the study at any time without penalty. Data collection occurred over a period of two weeks. Academic Advisors were emailed and asked to promote survey participation among their students verbally and through emails. About 3-4 email reminders were automatically generated and sent to students through the Mapworks web server. To increase the response rate, participants were offered incentives for participation. Completion of the survey took approximately 15 minutes. Survey data downloaded from 
Mapworks were stored on secured drives on password-protected computers. To ensure confidentiality, student data were aggregated and de-identified before analysis.

\subsection{Design and Statistical Analyses}

The research design was descriptive, cross-sectional and correlational. Data were analyzed using the Statistical Package for the Social Sciences (SPSS) version 24.0. Before analysis, data were checked for missing values and outliers. Cases that had a missing value in at least one of the items were dropped. Analyses were performed on cases that have the complete set of data. Pearson Product Moment Correlation was used to explore the relationship between criterion variables and predictor variables. Canonical correlation analysis (CCA) was conducted to determine if relationships exist among the predictor variables (spirituality, peer connections, social integration) and the criterion variables (academic resiliency, academic self-efficacy, academic integration, institutional commitment). The canonical correlation is the simple Pearson $r$ between the two synthetic variables, which were linearly combined from the observed variables (Figure 1).

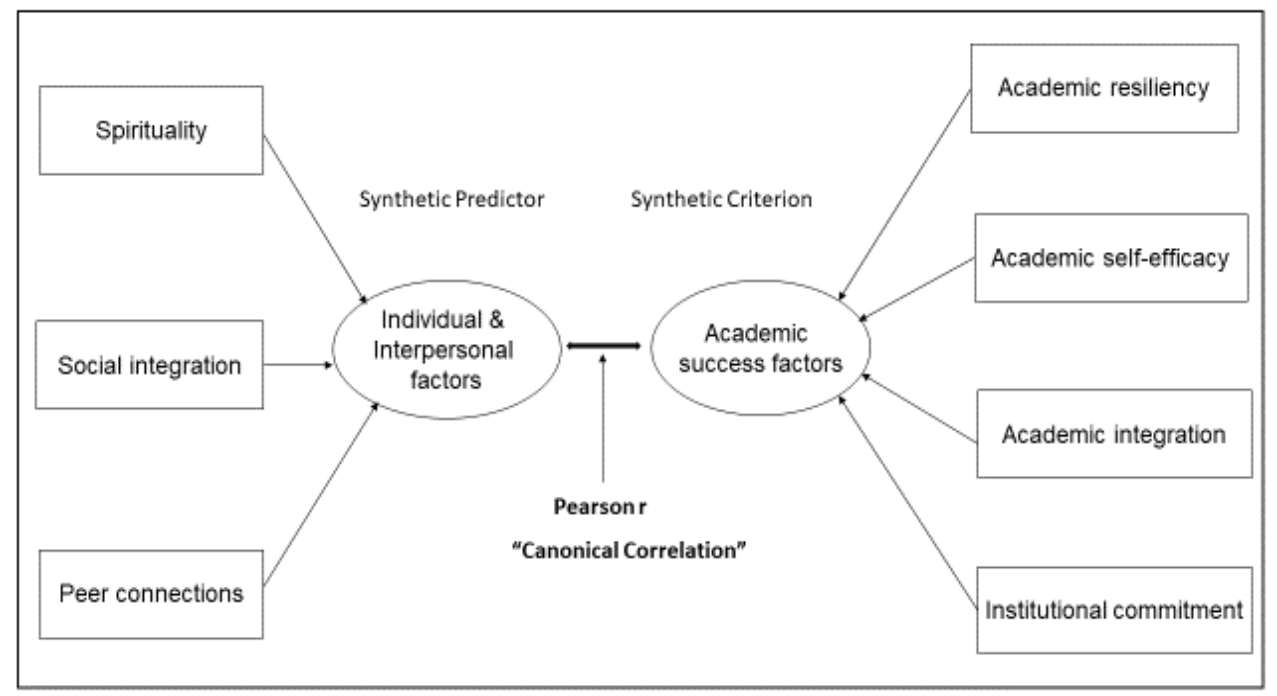

Figure 1. Illustration of the first function in a canonical correlation analysis with three predictors and four criterion variables

CCA is appropriate for use in this study because it allowed for simultaneous comparisons among the variables rather than requiring many statistical tests to be conducted (Sherry \& Henson, 2005). This reduces the likelihood of finding a relationship when it really does not exist in the population (Type 1 error). Only the functions that explained a reasonable amount of the relationship between the variable sets were considered for interpretation.

\section{Results}

\subsection{Demographics}

A total of 554 students completed the online survey from a population of 931. Listwise deletion was used to remove cases that have one or more missing values on key predictor and criterion variables resulting in a sample size of 372 and a response rate of $39.9 \%$. Of these, $13.2 \%$ (49) are $1^{\text {st }}$ year/Freshman, $30.1 \%$ (112) are sophomores, $27.0 \%$ (100) are juniors, and 29.7\% (111) are seniors. Participants' mean age was 21.40 (SD = 2.93). For race $63.0 \%$ of the participants identified as Caucasian $(\mathrm{n}=234), 7.3 \%$ identified as Black or African American $(\mathrm{n}=27), 12.4 \%$ identified as Asian $(\mathrm{n}=46), 8.5 \%$ identified as Hispanic or Latino $(\mathrm{n}=32), 4.8 \%$ were of two or more races $(n=18), 1.2 \%$ identified as nonresident Alien $(n=5), 2.4 \%$ identified as Other $(n=9)$, and one participant (.3\%) identified as American Indian or Alaska Native. For religious affiliation 22.3\% identified as Protestant $(n=83), 16.5 \%$ were Catholic $(n=61), 2.1 \%$ were Muslim $(n=8), 1.5 \%$ Buddhist $(n=5)$, 4.3\% Agnostic $(\mathrm{n}=16), 0.4 \%$ Hindu $(\mathrm{n}=1), 0.4 \%$ Jewish $(\mathrm{n}=1)$, and $26 \%$ reporting no religious affiliation $(\mathrm{n}=$ 97). About $34.4 \%$ of the participants had missing data on religion. Participants were from different schools with $125(33.7 \%)$ in School of Humanities, Arts, and Sciences (SHAS), 46.6\% $(\mathrm{n}=173)$ in Henrietta Schmoll School of Health (HSSH), and 16.8\% $(n=62)$ in School of Business and Professional Studies (SBPS). Twelve participants left this item blank. A total of 193 (52\%) participants live off campus, while 179 (48\%) live on campus. Participants' mean scores on predictor and criterion variables ranged from moderate to high. The means and standard deviations for the predictor and criterion variables are displayed in Table 1. 
Table 1. Means, Standard Deviations of Key Study Variables $(\mathrm{n}=372)$

\begin{tabular}{lll}
\hline Variable & Mean & Std. Deviation \\
\hline Spiritual well-being & 62.78 & 31.069 \\
Peer connections & 5.209 & 2.1963 \\
Social integration & 5.174 & 1.4348 \\
Academic integration & 5.952 & 1.4942 \\
Academic self-efficacy & 5.520 & 1.8708 \\
Academic resiliency & 6.180 & 0.7561 \\
Commitment to the institution & 6.491 & 0.8811 \\
\hline
\end{tabular}

\subsection{Bivariate Correlations between Key Variables}

The coefficients of correlations were computed to examine the associations between the key variables. The results show that spirituality significantly correlated with peer connections, social integration, academic resiliency, and academic self-efficacy but did not significantly correlate with academic integration and institutional commitment. This suggests that individuals who reported higher spirituality are likely to have greater connections with peers, faculty, and staff and are confident that they can do well in their courses if they work hard. Peer connections significantly correlated with social integration and academic resiliency, while social integration was significantly associated with academic resiliency. Suggesting that students who are very well connected and feel at home in school are likely to do what it takes to meet the academic goals they set at the beginning of the semester. Academic resiliency was associated with academic self-efficacy and institutional commitment showing that academic resilient students are likely to persevere and persist in school amidst academic difficulties. Academic self-efficacy and academic integration were both significantly associated with institutional commitment indicating that individuals who feel motivated and believe they can do well in class work are more likely to persist and complete their degree. Table 2 shows the correlations.

Table 2. Correlational Analysis of the Different Variables involved in the Study $(\mathrm{N}=372)$

\begin{tabular}{llllllll}
\hline Variables & $\mathbf{1}$ & $\mathbf{2}$ & $\mathbf{3}$ & $\mathbf{4}$ & $\mathbf{5}$ & $\mathbf{6}$ & $\mathbf{7}$ \\
\hline 1. Spiritual well-being & 1 & & & & & & \\
2. Peer connections & $.113^{*}$ & 1 & & & & & \\
3. Social integration & $.149^{* *}$ & $.507^{* *}$ & 1 & & & & \\
4. Academic resiliency & $.169^{* *}$ & $.184^{* *}$ & $.247^{* *}$ & 1 & & & \\
5. Academic self-efficacy & $.105^{*}$ & -0.065 & -0.081 & $.134^{* *}$ & 1 & & \\
6. Academic integration & -0.040 & 0.002 & -0.004 & 0.011 & 0.061 & 1 & \\
7. Commitment to the institution & -0.012 & 0.011 & 0.062 & $.138^{* *}$ & $.108^{*}$ & $.117^{*}$ & 1 \\
${ }^{*} p<.05 ; * * p<.01$ (2-tailed) & & & & & & &
\end{tabular}

\subsection{Canonical Correlations among Predictor and Criterion Variables}

Although bivariate correlations are useful in determining associations, they do not show the predictive power of the variable. Therefore, a canonical correlation analysis was appropriate in this case for exploring the relationships between two multivariate sets of variables measured on the same individual. The canonical correlation was conducted using individual and interpersonal level variables as predictors of academic success factors to evaluate the multivariate shared relationship between the two sets of variables. The analysis yielded three functions with squared canonical correlations $\left(\mathrm{R}_{\mathrm{C}}{ }^{2}\right)$ of $.088, .025$, and .002 for each successive function. Collectively, the full model across all functions was statistically significant using the Wilks's $\lambda=.887$ criterion, $\mathrm{F}(12,965.99)=3.721, \mathrm{p}<.001$. Because the Wilks's $\lambda$ represents the variance unexplained by the model, $1-\lambda$ yields the full model effect size in an $\mathrm{r}^{2}$ metric. Therefore, for the set of 3 canonical functions, the $\mathrm{r}^{2}$ type effect size was .113, which indicates that the full model explained $11.3 \%$ of the variance shared between the variable sets.

The dimension reduction analysis was used to test the hierarchical arrangement of functions for statistical significance. As noted earlier, only the full model (Functions 1 to 3 ) was statistically significant. Functions 2 to 3 , including Function 3 which was tested in isolation did not explain a statistically significant amount of shared variance between the variable sets, $\mathrm{F}(6,732.00)=1.667$ and $\mathrm{F}(2,367.00)=.300, \mathrm{p}>.05$, respectively.

Given the $\mathrm{R}_{\mathrm{C}}{ }^{2}$ effects for each function, only the first function was noteworthy in this study, and it explained $8.82 \%$ of the shared variance. The last two functions only explained $2.5 \%$ and $.2 \%$, respectively. Table 3 presents the 
standardized canonical function coefficients and structure coefficients for Function 1.

Table 3. Canonical Solution for Personal and Interpersonal Level Factors Predicting Academic Success Attributes

\begin{tabular}{lccl}
\hline & \multicolumn{3}{c}{ Function 1 } \\
\hline Variable & Coefficient & $\mathbf{r}_{\mathbf{S}}$ & $\mathbf{r}_{\mathbf{S}}{ }^{2}(\boldsymbol{\%})$ \\
\hline Academic resiliency & .991 & $\mathbf{. 6 0 0}$ & 92.16 \\
Academic self-efficacy & -.274 & -.139 & 1.93 \\
Academic integration & -.051 & -.051 & .26 \\
Institutional commitment & .047 & .149 & 2.22 \\
Academic success factors & & & 24.17 \\
$\mathrm{R}_{\mathrm{C}}{ }^{2}$ & & & 8.82 \\
Individual, Interpersonal factors & & & 4.44 \\
Spirituality & .334 & $\mathbf{. 4 7 2}$ & 22.3 \\
Social integration & .725 & $\mathbf{. 9 1 1}$ & 83.0 \\
Peer connections & .269 & $\mathbf{. 6 7 4}$ & 45.4 \\
\hline
\end{tabular}

Note. Coefficient $=$ standardized canonical function coefficient; $r_{S}=$ structure coefficient; $r_{S}^{2}$ structure coefficients squared or variance explained, $\mathrm{R}_{\mathrm{c}}{ }^{2}$ squared canonical correlation or amount of shared variance between the variable sets. Noteworthy structure coefficients (>.45) are in bold type.

Looking at the Function 1 coefficients, academic resiliency is the only contributor to the synthetic criterion variable, and this conclusion was supported by the squared structure coefficient $(92.16 \%)$. The contributions of academic self-efficacy, academic integration and institutional commitment to the synthetic criterion variable were very negligible. Regarding the predictor variable set, social integration and peer connections are the primary contributors to the predictor synthetic variable, with a secondary contribution by spirituality. Social integration, peer connections, and spirituality were all positively related to academic resiliency. These results indicate that the interpersonal level factors (social integration and peer connections) have more influence on academic resiliency than the intrapersonal factor (spirituality).

\section{Discussion}

\subsection{Relationships between Spirituality, Peer Connections, Social Integration and Academic Success Attributes}

This is the first study to the best of our knowledge that has explored the relative contributions of spirituality, peer connections, and social integration to academic resiliency, academic self-efficacy, academic integration, and institutional commitment of female college students. This is also the first study that has been conducted in an all-female faith-based higher institution. This study was conducted to understand the factors that may be associated with the academic success of this population of college students since so less is known about them. The present study used the Pearson's correlation to test the first three hypotheses that spirituality, peer connections, and social integration will be significantly correlated with academic resiliency, academic self-efficacy, academic integration, and institutional commitment. While the hypotheses were not fully supported, interesting findings emerged from the study. Results of the bivariate analyses revealed that participants who reported higher spirituality are more likely to be connecting well with teachers, staff, and people who share common interests with them. The sense of direction, support and meaning derived from these relationships may have likely boosted their belief and confidence to overcoming academic adversities to do well in school. That higher peer connections and social integration significantly correlated with academic resiliency suggest that female students in a faith-based higher institution who have a broader support network and a high sense of school belonging are more likely to work hard and do well even when a course or project is hard. None of the predictor variables (spirituality, peer connections, and social integration) correlated with institutional commitment, in contrast to the work of Morris (2002) which found that spirituality was significantly related to students' decision to remain or leave a Christian higher institution.

\subsection{Personal and Interpersonal Level Influence on Academic Success}

Canonical correlation was used to test the correlations among the predictor set (spirituality, peer connections, and social integration) and the criterion set (academic resiliency, academic self-efficacy, academic integration, and institutional commitment). Results of the analysis showed that both the predictor and criterion set significantly correlated with each other and explained $11.3 \%$ of the variance. This suggests that both individual (spirituality) and interpersonal (peer connections and social integration) level factors may be related to college students' 
academic success. Among the criterion variables, academic resiliency was the most important academic success attribute, and the two interpersonal level factors had the most influence on academic resiliency. It was surprising to find that spirituality contributed the least to academic resiliency. Results of the study supported hypothesis 4 .

\subsection{Social Integration and Peer Connections as Primary Predictors of Academic Resiliency}

A major significant finding of the present study was that social integration and peer connections were the primary predictors of academic resiliency, but not academic self-efficacy, academic integration, and institutional commitment. Social integration is about the degree to which students feel that they are fitting in, feel at home, and are satisfied with the social life on campus contributed the most $(83 \%)$ to academic resiliency. Peer connections is about the degree to which students are relating with people they like and those who share common interests with them explained $45.4 \%$ of the variance in academic resiliency. The warm interactions with one's peers and others may enhance academic resiliency and hence academic success. The findings of the present study suggest that students who are highly connected to other students, faculty, staff, developing friendships and adapting to the social way of life at the university are more likely to employ these resources to overcome academic challenges and succeed in school. Having these interactions may be a source of tangible, emotional, informational, and appraisal support that is likely to enhance the capability of a student to overcome life's obstacles including those related to school work. This finding is consistent with the work of Parks, (2016) which found that participation in faculty-led arts-based cocurricular activities provided the three external protective factors that foster resilience: caring relationships, high expectations, and meaningful participation. Likewise, Pan, Guo, Alikonis, and Bai (2008) found that college students who are academically and socially connected with faculty, staff, and their peers are more likely to perform well in school. Such multifaceted connections can help students build both personal and academic resilience leading to better academic performance and success. However, Rienties, et al., (2012) and Woosley and Miller (2009) argued that students who maximize their efforts to integrate socially might devote less time in academic activities and hence perform poorly in school.

\subsection{Spirituality as a Secondary Predictor of Academic Resiliency}

Spirituality surprisingly was a secondary contributor to academic resilience in the canonical correlation and explained $22.3 \%$ of the variance, whereas, in the bivariate analyses, it significantly correlated with both academic resiliency and academic self-efficacy. This finding suggests that students who reported higher spirituality scores may have a greater capacity to effectively deal with challenges, adversities, and setbacks experienced in the school setting. Thus, students who are highly spiritual are more likely to perform well and complete their degree despite academic challenges or other adversities. This finding is consistent with the work of Estanislao, RGC, and District (2017) which found that spiritual strength, belief in self, positive attitude, and adaptability contribute to the development of resilience of college students. The present study also agrees with the work of Constantine et al., (2006) which found that students tend to utilize their spiritual assets to cope with academic difficulties. Such spiritual assets include practices such as meditation, prayer, and self-reflection which tend to help students strengthen their inner life and nurture their resilience.

Similarly, Paul and Saha (2016) found that management students employed their spirituality tools such as meditation, practicing yoga, listening to spiritual music, and reading spiritual books to cope with academic stress. The study reported that when students engage in different spiritual practices, self-efficacy, hope, optimism, and resilience increases substantially, while stress minimizes. Conversely, self-efficacy, hope, optimism, and resilience remain unaffected for students who are not involved in any spiritual practices, and such students experience maximum stress. Although the findings of this study support the role of spirituality in strengthening academic resiliency, Morgan Consoli, Delucio, Noriega, \& Llamas (2015) found that spirituality was not a significant predictor of the resilience of Latino college students.

\subsection{Study Significance}

This research is the first of its kind to be conducted in an all-female faith-based higher institution. It is also the first to provide insight into the factors related to college women's academic success in a faith-based higher institution. This study went beyond exploring the bivariate relationships between the variables to exploring the multivariate relationships since academic achievement is influenced by multiple factors operating at different ecological levels. This study provided evidence that interpersonal level factors may be more pertinent to the academic success of college women in a faith-based higher institution than spirituality which is an intrapersonal level factor.

\subsection{Limitations}

This study has some limitations which provide opportunities for future research. First, a convenience sample of 
372 students in the faith-based higher institution who participated in the study is a little low; therefore, the findings may only be generalized to similar settings and population. Second, the use of cross-sectional design makes it difficult to determine causal relationships between the variables, but it provides a baseline for conducting similar studies in other faith-based higher institutions. Third, spirituality, social integration, and peer connections explained $11.3 \%$ of the variance in student academic success. Other factors such as economic security, having a well-educated parent, etc., may have contributed to the remaining $88.7 \%$ of the variance. Hence future studies should take into account such factors to fully understand college women's academic success Fourth, the results are based on a sample of female students at a mid-size Catholic women college. These findings may not generalize to other public women colleges or to co-educational colleges and universities. However, researchers may want to explore these issues in other college women samples. Finally, the SIRSW used in the study is a newly developed measure of spirituality. Although it demonstrated good reliability and validity in this sample of college students (Ekwonye, 2018), further testing of its predictive validity will add to its integrity as a measure of spirituality in college women. Therefore, caution must be used when attempting to generalize conclusions in other settings.

\subsection{Implications for Practice}

This study not only extends the findings of existing research that links social integration, peer connections, and spirituality to students' academic success, but provides evidence on the most important factor for academic resilience among female students attending a faith-based higher institution. Overall, the findings of the study suggest the need for college administrators to support the social and spiritual well-being of women on college campuses by creating a climate where students can feel at home and satisfied with their campus experience. At the intrapersonal level, college administrators can promote the development and implementation of the spiritual mentorship program. Such a program may focus on recruiting interested students as spiritual mentors and training them on different coping skills and spiritual practices. Afterward, have the spiritual mentors provide advice and emotional support to their fellow students to help strengthen their resiliency. The office of the student support services may organize interdenominational spiritual retreats to help reenergize students' sense of meaning and purpose in life, belief, and confidence in self. At the interpersonal level, college administrators can support the development of peer support groups with faculty as advisors. Such a program may not only promote student-faculty interactions but help students to feel at home on campus. Also, having a web-based peer support conducted using social media may be helpful. Such web-based peer support may involve sending words of encouragement and uplifting phrases through email or text messages by the peer mentors to their fellow students. These programs if implemented may help strengthen students' coping skills and broaden their social networks on campus.

\section{Conclusion}

This study provided an opportunity to explore both individual and social factors that contribute to academic resiliency, academic self-efficacy, academic integration, and institutional commitment of young women in a faith-based higher institution. The results revealed that individual-level attribute of spirituality and interpersonal level attribute of social integration should be jointly considered when developing programs that promote student's academic success in faith-based higher institution. By having a safe space to actively engage in different spiritual practices such as self-reflection, meditation, and prayer, students can develop the inner strengths and capacity to overcome different kinds of academic and other life's challenges to achieve positive outcomes. Engagement with other students, faculty, staff, and mentors on college campuses can provide students the social support that can help nurture their sense of resilience and self-efficacy.

\section{Acknowledgments}

I would like to thank Alvina Brueggemann, Ellen Richter-Norgel, Lindsay Whipple, Brian Dusbiber, and Cyprian Onyeihe for their guidance, assistance with data collection, and support of this research.

\section{References}

Abiola, T., \& Udofia, O. (2011). Psychometric assessment of the Wagnild and Young's resilience scale in Kano, Nigeria. BMC Research Notes, 4(1), 509. https://doi.org/10.1186/1756-0500-4-509

Arora, A. (2017). Women's Spirituality at CIIS: Uniting Integral and Feminist Pedagogies. Integral Education, Women's Spirituality and Integral Feminist Pedagogies, 13(1).

Asghari, F., Saadat, S., Atefi Karajvandani, S., \& Janalizadeh Kokaneh, S. (2014). The Relationship between Academic Self-Efficacy and Psychological Well-Being, Family Cohesion, and Spiritual Health among Students of Kharazmi University. Iranian Journal of Medical Education, 14(7), 581-593. 
Aune, K. (2011). Much less religious, a little more spiritual: The religious and spiritual views of third-wave feminists in the UK. Feminist Review, 97, 32-55. https://doi.org/10.1057/fr.2010.33

Bandura, A. (Ed.). (1995). Self-efficacy in changing societies. Cambridge university press. https://doi.org/10.1017/CBO9780511527692

Bandura, A., Barbaranelli, C., Caprara, G. V., \& Pastorelli, C. (2001). Self - efficacy beliefs as shapers of children's aspirations and career trajectories. Child development, 72(1), 187-206. https://doi.org/10.1111/1467-8624.00273

Beauvais, A. M., Stewart, J. G., DeNisco, S., \& Beauvais, J. E. (2014). Factors related to academic success among nursing students: A descriptive correlational research study. Nurse Education Today, 34(6), 918-923. https://doi.org/10.1016/j.nedt.2013.12.005

Bryant, A. N. (2007). Gender differences in spiritual development during the college years. Sex roles, 56(11-12), 835-846. https://doi.org/10.1007/s11199-007-9240-2

Bronfenbrenner, U. (1994). Ecological models of human development. International Encyclopedia of Education, $3(2), 37-43$.

Buchko, K. J. (2004). Religious beliefs and practices of college women as compared to college men. Journal of College Student Development, 45(1), 89-98. https://doi.org/10.1353/csd.2004.0004

Cavazos Jr, J., Johnson, M. B., \& Sparrow, G. S. (2010). Overcoming personal and academic

challenges: Perspectives from Latina/o college students. Journal of Hispanic Higher Education, 9(4), 304-316. https://doi.org/10.1177/1538192710380744

Constantine, M. G., Miville, M. L., Warren, A. K., Gainor, K. A., \& Lewis-Coles, M. A. E. (2006). Religion, spirituality, and career development in African American college students: A qualitative inquiry. The Career Development Quarterly, 54(3), 227-241. https://doi.org/10.1002/j.2161-0045.2006.tb00154.x

Denning, E. C., Brannan, D., Murphy, L. A., Losco, J. A., \& Payne, D. N. (2018). Not All Roles Are the Same: An Examination Between Work-Family-School Satisfaction, Social Integration, and Negative Affect Among College Students. Psi Chi Journal of Psychological Research, 23(2), 166-178. https://doi.org/10.24839/2325-7342.JN23.2.166

Dennis, J. M., Phinney, J. S., \& Chuateco, L. I. (2005). The role of motivation, parental support, and peer support in the academic success of ethnic minority first-generation college students. Journal of College Student Development, 46(3), 223-236. https://doi.org/10.1353/csd.2005.0023

Ekwonye, A. U. (2018, October). The Development and Validation of the Spiritual Impact Rating Scale for Women (SIRSW). Poster session presented at the 13th Annual Women's Health Research Conference, St. Paul, MN.

Ekwonye, A. U., Cahill, T., De Luca, D., \& Cabell, L. (2017). Exploring the multivariate relationships between adolescent depression and social support, religiosity, and spirituality in a faith-based high school. Health, 9(01), 38. https://doi.org/10.4236/health.2017.91004

Estanislao, S. A., RGC, R., \& District, L. E. A. (2017). Lasallian spirituality and resilience in Filipino college students: Relationship and resources. Revista Digital de Investigación Lasaliana-Revue numérique de Recherche lasallienne-Digital Journal of Lasallian Research, 14, 98-116.

Fife, J. E., Bond, S., \& Byars-Winston, A. (2011). Correlates and predictors of academic self-efficacy among African American Students. Education, 132(1).

Furrer, C. J., Skinner, E. A., \& Pitzer, J. R. (2014). The influence of teacher and peer relationships on students' classroom engagement and everyday motivational resilience. National Society for the Study of Education, 113(1), 101-123.

George, D., Dixon, S., Stansal, E., Gelb, S. L., \& Pheri, T. (2008). Time diary and questionnaire assessment of factors associated with academic and personal success among university undergraduates. Journal of American College Health, 56(6), 706-715. https://doi.org/10.3200/JACH.56.6.706-715

Gilligan, C. (1993). In a different voice: psychological theory and women's development. Cambridge, Mass.: Harvard University Press.

Gilligan, C. (2014). Moral injury and the ethic of care: Reframing the conversation about differences. Journal of Social Philosophy, 45(1), 89-106. https://doi.org/10.1111/josp.12050

Goldrick-Rab, S. (2010). Challenges and opportunities for improving community college student 
success. Review of Educational Research, 80(3), 437-469. https://doi.org/10.3102/0034654310370163

Grace, G. (2003). Educational studies and faith-based schooling: Moving from prejudice to evidence-based argument. British Journal of Educational Studies, 51(2), 149-167. https://doi.org/10.1111/1467-8527.t01-1-00231

Greenway, K. A. (2006). The role of spirituality in purpose in life and academic engagement. Journal of College and Character, 7(6). https://doi.org/10.2202/1940-1639.1212

Hill, P. C., \& Hood, R. W. Jr. (1999). Measures of religiosity. Birmingham, Al.: Religious Education Press.

Hodge, D. R. (2001). Spiritual assessment: A review of major qualitative methods and a new framework for assessing spirituality. Social work, 46(3), 203-214. https://doi.org/10.1093/sw/46.3.203

Hooker, S. A., Kevin, S. M., \& Kate, B. C. (2014). Multidimensional assessment of religiousness/spirituality and health behaviors in college students. The International Journal for the Psychology of Religion, 24(3), 228-240. https://doi.org/10.1080/10508619.2013.808870

Jones, L. (2005). What does spirituality in education mean?. Journal of College and Character, 6(7). https://doi.org/10.2202/1940-1639.1485

Khan, K., Ali, S., \& Kausar, Y. (2014). Spiritual well-being in relation to achievement motivation among students of science and commerce streams. Indian Journal of Health \& Wellbeing, 5(1).

Kuh, G. D., \& Gonyea, R. M. (2006). Spirituality, Liberal Learning, and College Student Engagement. Liberal Education, 92(1), 40-47.

Larrabee, M. J. (2016). An ethic of care: Feminist and interdisciplinary perspectives. Routledge.

Longman, C. (2018). Women's circles and the rise of the new feminine: Reclaiming sisterhood, spirituality, and wellbeing. Religions, 9(9). https://doi.org/10.3390/rel9010009

Martin, A. J., \& Dowson, M. (2009). Interpersonal relationships, motivation, engagement, and achievement: Yields for theory, current issues, and educational practice. Review of educational research, 79(1), 327-365. https://doi.org/10.3102/0034654308325583

Martin, A. J., \& Marsh, H. W. (2009). Academic resilience and academic buoyancy: Multidimensional and hierarchical conceptual framing of causes, correlates and cognate constructs. Oxford Review of Education, 35(3), 353-370. https://doi.org/10.1080/03054980902934639

Mehrinejad, S., Tarsafi, M., \& Rajabimoghadam, S. (2015). Predictability of students' resiliency by their spirituality. In 6th World Conference on Psychology, Counseling Guidance. Procedia-Social and Behavioral Sciences, 205, 396-400. https://doi.org/10.1016/j.sbspro.2015.09.024

Morgan Consoli, M. L., Delucio, K., Noriega, E., \& Llamas, J. (2015). Predictors of resilience and thriving among Latina/o undergraduate students. Hispanic Journal of Behavioral Sciences, 37(3), 304-318. https://doi.org/10.1177/0739986315589141

Morris, J. (2002). Academic integration, social integration, goal and institutional commitment, and spiritual integration as predictors of persistence at a Christian institution of higher education (Doctoral dissertation, Texas Tech University).

Nyhagen, L., \& Halsaa, B. (2016). Religion, gender and citizenship: Women of faith, gender equality and feminism. Springer. https://doi.org/10.1057/9781137405340

Pan, W., Guo, S., Alikonis, C., \& Bai, H. (2008). Do Intervention Programs Assist Students to Succeed in College?: A Multilevel Longitudinal Study. College Student Journal, 42(1).

Pargament, K. I. (2001). The psychology of religion and coping: Theory, research, practice. Guilford Press.

Parks, C. (2016). The Relationship Between At-Risk College Students' Participation in Arts-Based Cocurricular Activities and Academic Resilience. Northeastern University.

Pascarella, E. T., \& Terenzini, P. T. (1980). Predicting freshman persistence and voluntary dropout decisions from a theoretical model. The Journal of Higher Education, 51, 60-75. https://doi.org/10.2307/1981125

Pascarella, E. T., \& Terenzini, P. T. (1983). Predicting voluntary freshman year persistence/withdrawal behavior in a residential university: A path analytic validation of Tinto's model. Journal of Educational Psychology, 75, 215-226. https://doi.org/10.1037/0022-0663.75.2.215

Paul, M., \& Saha, P. (2016). Spirituality as a Potential Psychological Capital Tool to Deal with Academic Stress 
Among Management Students. IUP Journal of Organizational Behaviour, 15(4), 46-65.

Raju, D., \& Schumacker, R. (2015). Exploring student characteristics of retention that lead to graduation in higher education using data mining models. Journal of College Student Retention: Research, Theory \& Practice, 16(4), 563-591. https://doi.org/10.2190/CS.16.4.e

Reed, P. G. (1987). Spirituality and well - being in terminally ill hospitalized adults. Research in nursing \& health, 10(5), 335-344. https://doi.org/10.1002/nur.4770100507

Rienties, B., Beausaert, S., Grohnert, T., Niemantsverdriet, S., \& Kommers, P. (2012). Understanding academic performance of international students: the role of ethnicity, academic and social integration. Higher Education (00181560), 63(6), 685-700. https://doi.org/10.1007/s10734-011-9468-1

Robbins, S. B., Lauver, K., Le, H., Davis, D., Langley, R., \& Carlstrom, A. (2004). Do psychosocial and study skill factors predict college outcomes? A meta-analysis. Psychological bulletin, 130(2), 261. https://doi.org/10.1037/0033-2909.130.2.261

Rood, R. E. (2009). Driven to achieve: First-generation students' narrated experience at a private Christian college. Christian Higher Education, 8(3), 225-254. https://doi.org/10.1080/15363750802708494

Severiens, S., \& Wolff, R. (2008). A comparison of ethnic minority and majority students: Social and academic integration, and quality of learning. Studies in higher education, 33(3), 253-266. https://doi.org/10.1080/03075070802049194

Sherry, A., \& Henson, R. K. (2005). Conducting and interpreting canonical correlation analysis in personality research: A user-friendly primer. Journal of personality assessment, 84(1), 37-48. https://doi.org/10.1207/s15327752jpa8401_09

Shin, J. Y., \& Steger, M. F. (2016). Supportive college environment for meaning searching and meaning in life among American college students. Journal of College Student Development, 57(1), 18-31. https://doi.org/10.1353/csd.2016.0005

Skinner, E. A., \& Pitzer, J. R. (2012). Developmental dynamics of student engagement, coping, and everyday resilience. In Handbook of research on student engagement (pp. 21-44). Springer, Boston, MA. https://doi.org/10.1007/978-1-4614-2018-7_2

Tisdell, E. J. (2001). Spirituality in Adult and Higher Education. ERIC Digest.

Tinto, V. (1993). Leaving college: Rethinking the causes and cures of student attrition. Chicago, IL: The University of Chicago Press.

Tinto, V. (1998). Colleges as communities: Taking research on student persistence seriously. The Review of Higher Education, 21(2), 167-177.

Trainor, S. L. (2006). A Delicat: The Catholic College in America. Change: The Magazine of Higher Learning, 38(2), 14-21. https://doi.org/10.3200/CHNG.38.2.14-21

Waggoner, M. D. (2016). Spirituality and contemporary higher education. Journal of College and Character, 17(3), 147-156. https://doi.org/10.1080/2194587X.2016.1195752

Walker, K. L., \& Dixon, V. (2002). Spirituality and academic performance among African American college students. Journal of Black Psychology, 28(2), 107-121. https://doi.org/10.1177/0095798402028002003

Walter, K. L. (2000). Staying or leaving: A multilevel approach to explaining variation in persistence rates among christian college undergraduates. Unpublished doctoral dissertation. University of Arizona, Tucson.

Wayman, J. C. (2002). The utility of educational resilience for studying degree attainment in school dropouts. The Journal of Educational Research, 95(3), 167-178. https://doi.org/10.1080/00220670209596587

Weathers, E., McCarthy, G., \& Coffey, A. (2016). Concept analysis of spirituality: An evolutionary approach. Nursing Forum, 51(2), 79-96. https://doi.org/10.1111/nuf.12128

Woosley, S. A., \& Miller, A. L. (2009). Integration and institutional commitment as predictors of college student transition: Are third week indicators significant? College Student Journal, 43(4).

Woosley, S., \& Jones, D. (2011). The foundation of Mapworks: Research and theoretical underpinnings of Mapworks. 


\section{Copyrights}

Copyright for this article is retained by the author(s), with first publication rights granted to the journal.

This is an open-access article distributed under the terms and conditions of the Creative Commons Attribution license (http://creativecommons.org/licenses/by/4.0/). 